domain of science under whatever circumstances may present themselves.

"As laid down in its Statutes, the Council recognises the relations between pure and applied science. There is no doubt that both governments and industrial groups will in an ever increasing degree call upon scientists for elucidation of the manifold complexities and problems which human life and human relationship are presenting - problems, the most important of which perhaps are those of finding food, space in which to live and employment for the various peoples spread over the earth. If at the present moment an international organisation devoted to the solutions of these problems is still beyond our vision, and organisation constructed according to national systems must provisionally be strengthened for fear of losing hold of economic possibilities, it can be foreseen that the scientists of every country will be drawn more and more into these spheres of national organisation. The Council expresses its confidence that scientists, while giving their aid in meeting the needs of their own nations, will never lose sight of the international character of science as a whole, and will ever continue to keep in working order and to develop the connections necessary for international co-operation, even if severe shocks unhappily might come to threaten economic and political relations.

"In professing its faith in the possibility and the necessity of peace between the world's peoples, the Council points out that the "brotherhood of scientists" can be an important factor towards the establishment of a desire for mutual understanding and helpfulness in order to overcome the dangers involved in a too exclusive nationalism.

"The Council therefore, in emphasising the significance of science, both pure and applied, as a common treasure for all humanity, which can only be realised through a free-spirited co-operation of the most diverse elements, is of opinion that scientists of the whole world have a task of working for this understanding, and urges all allied organisations to give constant attention to this task."

The General Assembly accepted unanimously an invitation from the Royal Society to meet in London in 1937.

\title{
Obituary
}

\section{Mme. CurIe}

$\mathrm{M}$ ME. CURIE, whose death occurred on July 4 after a brief illness, held an outstanding position in science, for she had long been regarded as the foremost woman investigator of our age. Although her greatest scientific work, the discovery and isolation of radium, was done nearly thirty years ago, yet, as professor in the Sorbonne and director of the Radium Institute in Paris, Mme. Curie until the time of her death was actively engaged in researches on the physical and chemical properties of the radioactive bodies. At the same time, she was also director of a vigorous school of research which attracted investigators from many countries. During the last few years, she was engaged in preparing preparations of actinium much stronger than had previously been available, for the purpose of examining the fine structure of the $\alpha$-ray groups emitted by the products of this element. With the help of her colleague, Dr. Rosenblum, and the use of the large Paris electro-magnet, many new results of importance were obtained.

Marie Sklodowska was born at Warsaw on November 7, 1867, and received her early education in that city. Interested in science, she resolved, notwithstanding financial difficulties, to go to Paris to perfect her scientific training, and took lectures and examinations in the Sorbonne. In 1895 she married Pierre Curie, a young physicist in Paris who was making those highly original and fundamental contributions to magnetism and crystallography so well known to every student to-day. The young couple joined forces in their scientific work, which was carried out initially under difficult conditions, for laboratory arrangements were poor, and both had to undertake much teaching to gain a livelihood.

The turning point of the scientific career of Mme. Curie came as a consequence of the fundamental discovery of radioactivity by Henri Becquerel in Paris in 1896. He showed that the element uranium spontaneously emitted new types of penetrating radiation which darkened a photographic plate and discharged electrified bodies. This new discovery attracted the attention of Mme. Curie and, using the electric method as a means of quantitative analysis, she showed that the radioactivity of uranium was an atomic property. She also observed that the mineral pitchblende, from which uranium was separated, showed four to five times the activity due to the uranium alone. Since the activity of uranium was due to the atoms alone, this observation could only be explained by the presence of a new element or elements in the pitchblende much more active than uranium.

Boldly relying on this hypothesis, Mme. Curie made a systematic chemical analysis of pitchblende, using the electric method as a means of qualitative and quantitative analysis of the activity of her preparations. The first active element observed by these methods had properties allied to bismuth and was called polonium after her native country. She later discovered the presence of another element, happily named radium, which was similar in chemical properties to barium. We now know that radium is one of the long series of products of the radioactive transformation of uranium and exists in uranium minerals in about 1 part in 3 millions compared with uranium, and weight for weight shows an activity many million times that of uranium. The paper announcing this discovery was published in the Comptes rendus of 1898 under the names of M. and Mme. Curie and G. Bemont.

While at this stage, M. and Mme. Curie did all their scientific work together, it is natural to assume that Mme. Curie, as the chemist of the combination, was mainly responsible for the chemical work involved. She alone was responsible for the large-scale chemical work required to separate radium from radioactive residues in sufficient quantity to purify it and obtain its 
atomic weight-a splendid piece of work for which she was awarded a Nobel Prize in 1911. It may be recalled here that Mme. Curie is the only recipient of a second award, for she shared a Nobel Prize with her husband and Henri Becquerel in 1904 .

The discovery and isolation of radium was an event of outstanding significance to science from both the theoretical and practical points of view. The spontaneous emission of radiation from this element was so marked that not only was it diffi. cult at first to explain but also, what was more important, still more difficult to explain away. The discovery of polonium and radium prepared the way for the ultimate explanation of radioactivity in terms of the spontaneous transformation of the radioactive bodies. Moreover, radium, in virtue of the radioactive emanation and other radioactive products into which it is transformed, has proved an invaluable source of great intensity for a study of the effects of the $\alpha-, \beta$ - and $\gamma$-rays in their passage through matter, and has thus played an important part in the growth of our knowledge of the internal structure of atoms in general. In addition, radium, in consequence of the highly penetrating $\gamma$-rays emitted from its products, has been widely used for therapeutic purposes and has proved an invaluable adjunct in the treatment of cancerous growths. Indeed, the greater part of the radium now separated on a commercial scale is utilised in the hospitals of the world for this purpose. Mme. Curie throughout her life actively promoted this use of her discovery to alleviate suffering, and during the War personally devoted herself to this remedial work-possibly at the expense of her own health.

Space does not allow me to mention more than a few of her numerous investigations in the field of radioactivity. She was for many years deeply interested in studying the chemical properties of the first element she discovered-polonium-and in developing methods for obtaining powerful sources of this element in the form of a thin film. Such active sources of polonium have proved of great use in later years in studying the transforma. tions of matter by the action of $\alpha$-particles, for the experiments are not complicated by the intense emission of $\beta$ - and $\gamma$-rays which arise from sources like radium $(B+C)$ and thorium $(B+C)$. It was with the aid of these strong polonium sources that her son-in-law and daughter, M. and Mme. Curie-Joliot, have recently studied with such success the production of neutrons and induced radioactivity by the action of $\alpha$-particles.

Mme. Curie retained her enthusiasm for science and scientific investigation throughout her life. She was an indefatigable worker and was never happier than in discussing scientific problems with her friends. All her publications are characterised not only by accuracy and skill in experimentation but also by marked critical power in the interpretation of the experimental results. Quiet, dignified and unassuming, she was held in high esteem and admiration by scientific men through. out the world, and was a welcome member of scientific conferences, in many of which she took an active part. She was a member of the Conseil du Physique Solvay from 1911 until her death. Since 1922 she had been a member of the Com. mittee of Intellectual Co-operation of the League of Nations, and made many visits to Geneva.

The life of Mme. Curie was not without serious trials and tragedy, for her husband lost his life in a street accident in 1906. Immediately afterwards she was called to assume the directorship of the new Radium Institute named the 'Laboratoire Curie' which had been built specially for Pierre Curie and herself. She was made professor in the Sorbonne-the first time that a woman had gained this position. She was a clear and attractive speaker, and her lectures in the Sorbonne were widely attended not only by students of science but also by the educated public. In her later years, it was a source of pleasure and pride to her to watch the fine discoveries made by her daughter Irene and her daughter's husband in collaboration in her own laboratory. In a sense, history had repeated itself.

The importance of the pioneer work of M. and Mme. Curie in radioactivity was promptly recognised by the scientific world. In 1903, the Royal Society awarded them its Davy Medal. It is of interest to note that in 1903, M. and Mme. Curie came to London and M. Curie gave a lecture before the Royal Institution on the properties of radium. On this occasion, with the help of Sir James Dewar, the heat emission of radium at the low temperature of liquid oxygen was demonstrated for the first time. Mme. Curie was awarded numerous honorary degrees and was made honorary member of many societies both in Great Britain and abroad. In her last visit to England in 1929, she received the freedom of the city of Glasgow as well as an honorary doctorate of laws from the University. She was invited by the women of the United States to visit them in 1921 ; they presented her with a gram of radium in recognition of her discoveries, and in order to allow her to extend her investigations. She was everywhere received with great honour and repeated her visit in 1928 .

The many friends of Mme. Curie throughout the world, who admired her not only for her scientific talents but also for her fine character and personality, lament the untimely removal of one who had made such great contributions to knowledge, and, through her discoveries, to the welfare of mankind.

RUTHERFORD.

We regret to announce the following deaths :

M. Benjamin Baillaud, honorary director of the Paris Observatory, and an associate of the Royal Astronomical Society, on July 8, aged eighty-six years.

Prof. F. W. Burstall, emeritus professor ${ }^{\circ}$ of mechanical engineering in the University of Birmingham, and vice-principal of the University in 1925-31, an authority on gas engines, on July 15, aged sixty-eight years. 